\title{
Analyzing Citation and Research Collaboration Characteristics of Faculty in Aerospace, Civil and Environmental, Electrical and Computer, and Mechanical Engineering
}

\section{Li Zhang}

\begin{abstract}
This article investigates citation and research collaboration habits of faculty in four engineering departments. The analysis focuses on similarities and differences among the engineering disciplines. Main differences exist in the use of conference papers and technical reports. The age of cited materials varies by discipline and by format. Regarding faculty connection with other subjects, the study finds that aerospace and mechanical engineering faculty collaborate more often with researchers outside their fields, while civil and environmental faculty, as well as electrical and computer engineering faculty, are more likely to cooperate with peers in their fields. Lists of highly cited journals are generated. The paper also provides suggestions for collection management, research assistance, and outreach efforts.
\end{abstract}

\section{Introduction}

Robust research support and services require a good understanding of information needs of academic library users: students, faculty, and the broader research community. To offer the best services possible, librarians strive to find information use habits among various user groups. Aside from observing library use patterns at their daily jobs and communicating informally (for example: face to face or via e-mail) with researchers, academic librarians conduct questionnaire surveys, interviews, and focus groups to discover library users' information-seeking behavior. In addition, librarians periodically gather usage statistics to identify how library materials are used. Some examples of such statistics are electronic resources usage reports from vendors and internally collected usage data concerning circulation, interlibrary loan, and "hold" requests placed in a library's catalog. Of the data approaches, citation analysis is another means that librarians employ to investigate the use of research resources. Despite its limita-

Li Zhang is Associate Professor/Science E Engineering Librarian at Mississippi State University; e-mail: lzhang@library.msstate.edu. (C2018 Li Zhang, Attribution-NonCommercial (http://creativecommons.org/ licenses/by-nc/4.0/) CC BY-NC. 
tions, citation analysis can provide valuable insights into the process of selecting and/ or deselecting library materials, and citation analysis can also serve as a user study, helping librarians design targeted programs and services.

One of the primary roles of academic libraries is to support faculty research. With frequent new subscription requests from faculty, but constrained library budgets and increasing costs of research materials, it becomes more critical for librarians to understand what resources are really being used in faculties' scholarly works. Keeping in mind that academic disciplines differ in their ways of conducting research and using information resources, the current study uses citation and content analysis methods to examine and compare how faculty at Mississippi State University (MSU) in the departments of aerospace, civil and environmental, electrical and computer, and mechanical engineering use research materials, and how the engineering faculty collaborate with researchers outside their fields. The purpose of this citation and collaboration study is to learn more about the engineering faculty's scholarly work and communication, identify essential resources for these fields, and determine the library's collection weaknesses. The study endeavors to provide practical information and comparable data for liaison and subject librarians with responsibilities in collection management and research services support.

\section{Review of Related Literature}

In the library literature, a vast majority of citation studies have explored graduate students' characteristics and information needs, using theses and dissertations as data sources. Among the studies pertinent to engineering students, some have particularly researched citation habits exhibited in aerospace, civil, electrical, and mechanical engineering theses and/or dissertations. For example, by analyzing citations in 25 theses and dissertations from the civil engineering department of University of Arkansas during 2003 and 2004, Kirkwood observed a relatively high use of government documents and technical reports by this engineering student group. ${ }^{1}$ Several other studies, however, checked more than one engineering subdiscipline mentioned above to find out graduate students' information use patterns. In an investigation of 250 master's theses accepted between 2000 and 2004 from eight engineering departments at MSU, Williams and Fletcher noticed distinctive citation practices among engineering subdisciplines with respect to citation format and age. ${ }^{2}$ Similarly, Fransen studied 123 theses and dissertations submitted from the aerospace engineering, electrical engineering, and computer science departments at University of Minnesota during 2008 and 2010, and her findings confirmed that citation format and age varied from one engineering subdiscipline to another. ${ }^{3}$ A more recent citation analysis of engineering theses was conducted by Brush for the chemical, civil, electrical, and mechanical engineering departments of Rowan University for the period of 2002 and 2010. The author discovered that mechanical and civil engineering students tended to use more "other sources" (that is to say, nonjournal, book, or conference proceeding materials), and electrical engineering students cited books significantly. ${ }^{4}$

Compared to graduate students, faculty may have distinctive research patterns. Only a handful of citation analyses have focused on the information-seeking behavior of engineering faculty/professional engineers. Some of these studies sought to identify citation patterns for the general engineering field, whereas the others looked at specific subfields of engineering, including the fields that are being investigated in this current article.

Eugene Garfield, a pioneer in the field of citation analysis, examined highly cited engineering literature in his essays published in 1975 and 1976, respectively. He found that books were cited more often than journal articles. ${ }^{5}$ Without surprise, Garfield also 
noticed that a small number of journals accounted for almost half of the total references cited in engineers' research. ${ }^{6}$ His finding backed up Bradford's Law of Scattering. Similar to Garfield's approach not restricting to any subdisciplines of engineering, Musser and Conkling, in their 1996 study of citations from journals in sixteen engineering fields, analyzed referenced materials by format and age to identify general citation characteristics for engineering as a single discipline. The authors proved that engineers used a variety of material types in their scholarly works and different types of materials aged at different rates. ${ }^{7}$ About 20 years later, Young replicated Musser and Conkling's study and noticed little change compared to the 1996 study, with regard to types of materials consulted by engineers and citation ages for different materials. ${ }^{8}$

Concentrating on a specific subdiscipline, electrical and electronics engineering, Coile analyzed references in several major journals in this field and developed a list of "source journals" ranked by number of citations. ${ }^{9}$ In his subsequent citation study of IEEE publications, Coile announced that periodicals, books, and conferences were highly cited sources by electrical and electronics engineers. ${ }^{10}$ Another study concerning the electrical engineering subdiscipline is an analysis of citation behavior of Korean electrical and electronics engineers. Likewise, the author stated that Korean electrical engineers cited journals, books, and conference proceedings more frequently than other materials and claimed that thirteen titles comprised core journals and conference proceedings. ${ }^{11}$ No newer citation studies (that is to say, published after 2000) could be found that were specifically focusing on electrical and computer engineering faculties' citation behavior. However, a related study provided some interesting findings. In his investigation of the literature of computer science, a field pertinent to electrical and computer engineering, Sjøberg pointed out that computing research did not age "more quickly than research in other disciplines."12

To understand aerospace engineering researchers' information use, Sridhar looked at both publishing and citing features of researchers at the Indian Space Research Organization Satellite Center and reported that journals, books, and technical reports were the major sources from which the Indian aerospace engineering researchers cited, although the researchers mostly published in conference papers and journal articles. ${ }^{13}$ Recently, Stephens et al. examined publications of aerospace engineering faculty at Texas A\&M University and reaffirmed the importance of journal articles and conference papers to engineering researchers. The authors further analyzed journal subject dispersion using the Library of Congress Classification and contended that aerospace engineering faculty used sources from various disciplines. ${ }^{14}$

Conducting a study similar to those of Musser/Conkling and Young but focusing on a subfield of engineering (civil engineering), Curtis investigated citations from six civil engineering journals and noted that civil engineering researchers cited journals most frequently, followed by monographs and conference papers. He also found that half of all citations except monographs were less than ten years old. ${ }^{15}$ Particularly interested in the age of citations, Spence, Mawhinney, and Barsky explored publications from faculty in civil engineering and computer science departments at three Canadian universities and proclaimed that materials needed to be retained at least 25 years to "cover $90 \%$ of faculty citations." 16

The only study found that was associated with the citation activities of mechanical engineering faculty or mechanical professional engineers is a comparative study of publishing and authorship patterns of Korean mechanical engineers and physicists. The author remarked that mechanical engineers used journals the most, followed by a combined category named "books and reports," and then proceedings. ${ }^{17}$ In a most recent cross-discipline study, by comparing citation data from external professional journal literature with internal dissertations in several STEM subfields (mostly engi- 
neering subfields), Kelly revealed that citation practices varied between professional engineering researchers and local doctoral students; she further discussed possible serial-to-monograph ratios based on the observation. ${ }^{18}$

Nowadays, interdisciplinary collaboration among researchers in different subject domains is common. Many studies have explored such kind of scholarly collaboration from a variety of perspectives; however, it seems that no previous citation analyses have particularly looked at engineering faculties' collaboration patterns being investigated in this current study.

\section{Objectives}

This study is based on and compares publications of faculty in the departments of aerospace, civil and environmental, electrical and computer, and mechanical engineering at MSU. The analysis will address the following research questions:

- Which types of research material do the faculty often use in their scholarly works?

- What are the highly cited journals in the engineering disciplines and associated departments? Are there any overlaps?

- What is the age range of frequently cited materials?

- Are the citation practices similar or different across the engineering subfields?

- With which other fields do the engineering faculty conduct collaborative research?

\section{Methods}

All faculty members at different ranks in the examined engineering fields were identified from departmental websites. The study did not consider publications from emeritus professors, instructors, and visiting scholars, because a) few publications were produced from the time period studied; $b$ ) if there were, the research works found from these groups mainly centered on engineering education and were mostly published in one journal; and c) visiting professors' citation patterns cannot truly reflect the needs of the faculty at MSU. Likewise, a professor who is affiliated with three academic institutions was excluded from the study. Another professor, who had an extraordinary research output that possessed extremely large number of citations, was also excluded from the analysis to avoid getting skewed results.

The current study acquired faculty publications from a major citation database, Elsevier's Scopus, rather than using faculty CVs, since many of them were outdated. It should be pointed out that, if time permits, engineering-specific databases also need to be searched to capture as comprehensive information as possible. In Scopus, we conducted an author and institution affiliation search to collect publications by each identified faculty member in the engineering departments. The study selected and retrieved only original articles and conference papers published during the period from 2013 to 2015 for analysis. Review articles were ruled out due to the nature of such kinds of papers. Cited references in each faculty member's articles and conference papers were exported from Scopus into Excel spreadsheets. Ultimately, a total of 12,908 raw citations comprised four datasets/Excel files, grouped by discipline/department: Aerospace Engineering, Civil-Environmental Engineering, Electrical-Computer Engineering, and Mechanical Engineering. Citations in each file were organized by author, year, source, and ISSN. We checked, searched, and updated incomplete citations imported from Scopus. Still, a total of 91 records from the four groups lacked sufficient information and were removed from analysis. Next, journal abbreviations were changed to full titles to ensure consistency throughout the datasets. MatLab was used to remove duplicates. Duplicated citations were found in the following 
situations: a) same references appeared twice, in faculties' conference papers and the subsequent journal articles they published, reporting the same information; b) the same work was presented at several associated conferences and was reproduced in multiple conference proceedings (with same references). Such redundant citations can distort the actual use of sources. The cleaned datasets coincidentally had a total of 10,000 citations. Classification for cited references by material format or type was vague in Scopus (for example, conference papers were often designated as journal articles). We then manually examined each citation and coded the total citations into eight different source types.

\section{Results}

\section{Types of Sources Cited}

Publications totaling 734 (378 journal articles, 356 conference papers) during the studied time period were identified. The study divided the wide variety of cited references into the following categories: journal articles, books or book chapters, conference papers, technical reports (including reports produced by government agencies), dissertations or theses, standards, websites, and other sources (government documents that are not technical reports, patents, trade magazines, newspaper, software user guides, and other; see table 1).

Across all the examined disciplines, journals were the most highly cited source type. Particularly in civil and environmental as well as mechanical engineering, more than three quarters of citations are to journal articles. Conference papers were the second favorite type of research materials for all, except for civil and environmental engineering faculty. Without surprise, conferences played an especially important role in electrical and computer engineering faculties' research, accounting for almost one third $(29.0 \%)$ of their total citations.

Books and technical reports were also regularly cited. But rankings of these two formats varied by discipline. Compared to colleagues in three other departments, civil and environmental engineering faculty cited more technical reports than conference papers, and technical reports became their second most preferred source material (7.4\%). Mechanical engineering faculty also consulted technical reports relatively often (but after conference papers), with about 5 percent of citations to this type of research material. As for the use of books, among the disciplines, the percentages of book citations varied from lowest $(4.2 \%)$ in mechanical engineering to highest $(9.9 \%)$ in aerospace engineering.

\begin{tabular}{|l|c|c|c|c|c|c|c|c|}
\hline \multicolumn{7}{|c|}{ TABLE 1 } \\
\hline $\begin{array}{c}\text { Engineering } \\
\text { Discipline }\end{array}$ & Journal & $\begin{array}{c}\text { Book/ } \\
\text { Book } \\
\text { Chapter }\end{array}$ & $\begin{array}{c}\text { Conference } \\
\text { Paper }\end{array}$ & $\begin{array}{c}\text { Technical } \\
\text { Report }\end{array}$ & $\begin{array}{c}\text { Theses/ } \\
\text { Dissertations }\end{array}$ & Standard & $\begin{array}{c}\text { Web- } \\
\text { site }\end{array}$ & Other* \\
\hline Aerospace & $67.4 \%$ & $9.9 \%$ & $12.1 \%$ & $4.4 \%$ & $1.9 \%$ & $1.0 \%$ & $1.7 \%$ & $1.7 \%$ \\
\hline $\begin{array}{l}\text { Civil \& } \\
\text { Environmental }\end{array}$ & $76.9 \%$ & $5.0 \%$ & $6.2 \%$ & $7.4 \%$ & $0.7 \%$ & $1.2 \%$ & $0.7 \%$ & $1.9 \%$ \\
\hline $\begin{array}{l}\text { Electrical \& } \\
\text { Computer }\end{array}$ & $55.8 \%$ & $6.6 \%$ & $29.0 \%$ & $2.0 \%$ & $1.0 \%$ & $0.6 \%$ & $3.3 \%$ & $1.6 \%$ \\
\hline Mechanical & $76.5 \%$ & $4.2 \%$ & $10.6 \%$ & $4.9 \%$ & $0.7 \%$ & $0 \%$ & $1.9 \%$ & $1.2 \%$ \\
\hline $\begin{array}{l}\text { *Include trade magazines, government documents that are not technical reports, patents, } \\
\text { newspaper, software user guides, and other. }\end{array}$ & & & & & & & \\
\hline
\end{tabular}


For other material types used less often, web citations showed a higher rate in electrical and computer engineering research works, ranking ahead of technical reports. On the other hand, aerospace engineering faculty seemed to reference dissertations or theses relatively frequently. With regard to standards, mechanical engineering faculty, surprisingly, made the most infrequent use of this type of resource, showing only three citations.

\section{Highly Cited Journals}

The current study attempted to compile lists of faculty most often cited journals for the four engineering departments by ranking citation counts of journals. The study presented, in tables $2-5$, the common journals that were cited by at least two faculty members in each department and that had citation counts of five times and more. Across all fields, an average of 22 percent of journals are unique titles, with electrical and computer engineering showing a slightly higher rate $(24 \%)$. Within aerospace and mechanical engineering faculties' publications, there were respectively 321 and 468 unique journal titles. In table 2, the 37 frequently consulted journals by aerospace engineering faculty accounted for 50 percent of their total journal citations, whereas 58 journals in table 5 made up about 51 percent of all journal citations that mechanical engineering faculty referenced. With respect to the remaining disciplines, out of 379 different titles, 36 frequently used journals constituted nearly 54 percent of the total journal citations referenced by civil and environmental engineering faculty, and 38 out of 349 unique titles contributed to a little more than 58 percent of the journals cited by electrical and computer engineering faculty (see tables 3 and 4). The above findings indicate that the faculty's journal use patterns correspond to Bradford's Law: a small number of core journals can cover a large portion of citations.

\begin{tabular}{|l|l|c|c|c|}
\hline \multicolumn{5}{|c|}{ TABLE 2 } \\
\hline \multicolumn{1}{|c|}{ Journal Name } & $\begin{array}{c}\text { No. of } \\
\text { Citations }\end{array}$ & $\%$ & $\begin{array}{c}\text { Cumulative } \\
\%\end{array}$ \\
\hline Rank & \multicolumn{1}{|c|}{} & \multicolumn{1}{|c|}{} \\
\hline 1 & AIAA Journal* & 84 & 5.6 & 5.6 \\
\hline 2 & Composites Science and Technology* & 68 & 4.6 & 10.2 \\
\hline 3 & Journal of Composite Materials* & 54 & 3.6 & 13.8 \\
\hline 4 & Structural and Multidisciplinary Optimization & 45 & 3.0 & 16.8 \\
\hline 5 & Journal of Fluid Mechanics* & 43 & 2.9 & 19.7 \\
\hline 6 & $\begin{array}{l}\text { Computer Methods in Applied Mechanics and } \\
\text { Engineering* }\end{array}$ & 33 & 2.2 & 21.9 \\
\hline 7 & $\begin{array}{l}\text { Journal of Mechanical Design, Transactions of } \\
\text { the ASME }\end{array}$ & 29 & 2.0 & 23.9 \\
\hline 8 & Journal of Aircraft & 27 & 1.8 & 25.7 \\
\hline 9 & Journal of Computational Physics & 26 & 1.7 & 27.4 \\
\hline 10 & $\begin{array}{l}\text { Composites Part A: Applied Science and } \\
\text { Manufacturing }\end{array}$ & 22 & 1.5 & 28.9 \\
\hline 11 & Engineering Fracture Mechanics & 21 & 1.4 & 30.3 \\
\hline 12 & International Journal of Fatigue & 20 & 1.3 & 31.6 \\
\hline 13 & Journal of Applied Polymer Science & 1.2 & 32.8 \\
\hline
\end{tabular}




\begin{tabular}{|c|c|c|c|c|}
\hline \multicolumn{5}{|c|}{$\begin{array}{c}\text { TABLE } 2 \\
\text { Aerospace Engineering Faculty Often Cited Journals by Citation Count }\end{array}$} \\
\hline Rank & \begin{tabular}{|l|} 
Journal Name \\
\end{tabular} & $\begin{array}{c}\text { No. of } \\
\text { Citations }\end{array}$ & $\%$ & $\begin{array}{l}\text { Cumulative } \\
\%\end{array}$ \\
\hline 13 & Composite Structures & 18 & 1.2 & 34.0 \\
\hline 14 & Journal of Materials Processing Technology & 17 & 1.1 & 35.1 \\
\hline 14 & Carbon & 17 & 1.1 & 36.2 \\
\hline 14 & Renewable Energy & 17 & 1.1 & 37.3 \\
\hline 15 & Journal of Guidance, Control, and Dynamics* & 16 & 1.1 & 38.4 \\
\hline 16 & Progress in Aerospace Sciences & 15 & 1.0 & 39.4 \\
\hline 16 & International Journal of Solids and Structures* & 15 & 1.0 & 40.4 \\
\hline 17 & Energy Conversion and Management & 13 & 0.9 & 41.3 \\
\hline 18 & $\begin{array}{l}\text { International Journal for Numerical Methods in } \\
\text { Engineering* }\end{array}$ & 12 & 0.8 & 42.1 \\
\hline 19 & Polymer* & 11 & 0.7 & 42.8 \\
\hline 19 & Journal of Applied Mechanics* & 11 & 0.7 & 43.5 \\
\hline 19 & Physics of Fluids* & 11 & 0.7 & 44.2 \\
\hline 19 & Computational Materials Science & 11 & 0.7 & 44.9 \\
\hline 20 & Smart Materials and Structures* & 10 & 0.7 & 45.6 \\
\hline 20 & $\begin{array}{l}\text { International Journal for Numerical Methods in } \\
\text { Fluids }\end{array}$ & 10 & 0.7 & 46.3 \\
\hline 21 & Computers and Structures & 9 & 0.6 & 46.9 \\
\hline 21 & $\begin{array}{l}\text { Proceedings of the Institution of Mechanical } \\
\text { Engineers, Part D: Journal of Automobile } \\
\text { Engineering }\end{array}$ & 9 & 0.6 & 47.5 \\
\hline 22 & International Journal of Impact Engineering & 8 & 0.5 & 48.0 \\
\hline 22 & Journal of Applied Physics* & 8 & 0.5 & 48.5 \\
\hline 22 & Journal of the Mechanics and Physics of Solids* & 8 & 0.5 & 49.0 \\
\hline 23 & Wind Energy & 7 & 0.5 & 49.5 \\
\hline 24 & International Journal of Crashworthiness & 5 & 0.3 & 49.8 \\
\hline 24 & International Journal of Fracture & 5 & 0.3 & 50.1 \\
\hline 24 & Structural Safety & 5 & 0.3 & 50.4 \\
\hline
\end{tabular}

\section{Age Distribution of Most Cited Sources}

The study also analyzed the age distribution of four most frequently cited source types: journals, books, conference papers, and technical reports. Across all disciplines, more than 50 percent of the above source types were published in the past 15 years-excluding the book citation category in mechanical engineering, which revealed only 34 percent. In fact, more than 55 percent of conference papers cited in all fields but aerospace engineering were only 5 years old or younger. By contrast, the majority (more than two thirds) of book citations across the disciplines were within 20 years old. 


\begin{tabular}{|c|c|c|c|c|}
\hline \multicolumn{5}{|c|}{$\begin{array}{c}\text { TABLE } 3 \\
\text { Civil \& Environmental Engineering Faculty Often Cited Journals by Citation Count }\end{array}$} \\
\hline Rank & Journal Name & $\begin{array}{c}\text { No. of } \\
\text { Citations }\end{array}$ & $\%$ & $\begin{array}{c}\text { Cumulative } \\
\%\end{array}$ \\
\hline 1 & Ecological Engineering & 172 & 10.1 & 10.1 \\
\hline 2 & Bioresource Technology & 75 & 4.4 & 14.5 \\
\hline 3 & Water Research** & 58 & 3.4 & 17.9 \\
\hline 4 & Environmental Science and Technology** & 57 & 3.4 & 21.3 \\
\hline 5 & Desalination & 43 & 2.5 & 23.8 \\
\hline 6 & Transportation Research Record & 40 & 2.4 & 26.2 \\
\hline 7 & Applied Energy & 38 & 2.2 & 28.4 \\
\hline 8 & Journal of Environmental Quality** & 35 & 2.1 & 30.5 \\
\hline 9 & Ecological Modelling & 33 & 1.9 & 32.4 \\
\hline 10 & $\begin{array}{l}\text { Journal of Geotechnical and Geoenvironmental } \\
\text { Engineering }\end{array}$ & 30 & 1.8 & 34.2 \\
\hline 11 & Renewable Energy & 29 & 1.7 & 35.9 \\
\hline 12 & Water Science and Technology** & 26 & 1.5 & 37.4 \\
\hline 13 & Journal of Hydrology & 25 & 1.5 & 38.9 \\
\hline 14 & Renewable and Sustainable Energy Reviews & 23 & 1.4 & 40.3 \\
\hline 15 & Energy Conversion and Management & 22 & 1.3 & 41.6 \\
\hline 15 & Journal of Materials in Civil Engineering & 22 & 1.3 & 42.9 \\
\hline 16 & Journal of Environmental Engineering** & 18 & 1.1 & 44.0 \\
\hline 17 & Fuel & 17 & 1.0 & 45.0 \\
\hline 18 & Water Resources Research** & 16 & 0.9 & 45.9 \\
\hline 19 & Journal of Hazardous Materials** & 15 & 0.9 & 46.8 \\
\hline 20 & Energy and Fuels & 12 & 0.7 & 47.5 \\
\hline 21 & $\begin{array}{l}\text { Transactions of the American Society of } \\
\text { Agricultural Engineers }\end{array}$ & 11 & 0.6 & 48.1 \\
\hline 22 & Journal of the American Oil Chemists' Society & 10 & 0.6 & 48.7 \\
\hline 23 & Water Management & 9 & 0.5 & 49.2 \\
\hline 23 & Fuel Processing Technology & 9 & 0.5 & 49.7 \\
\hline 24 & Construction and Building Materials & 8 & 0.5 & 50.2 \\
\hline 24 & Science** & 8 & 0.5 & 50.7 \\
\hline 25 & Journal of Geophysical Research B: Solid Earth & 7 & 0.4 & 51.1 \\
\hline 26 & Industrial and Engineering Chemistry Research & 6 & 0.4 & 51.5 \\
\hline 26 & Transactions of the ASABE & 6 & 0.4 & 51.9 \\
\hline 27 & Engineering Geology & 5 & 0.3 & 52.2 \\
\hline 27 & International Journal of Greenhouse Gas Control & 5 & 0.3 & 52.5 \\
\hline 27 & Journal of Power Sources & 5 & 0.3 & 52.8 \\
\hline 27 & Solar Energy & 5 & 0.3 & 53.1 \\
\hline 27 & Progress in Energy and Combustion Science & 5 & 0.3 & 53.4 \\
\hline 27 & Nature & 5 & 0.3 & 53.7 \\
\hline
\end{tabular}




\begin{tabular}{|c|c|c|c|c|}
\hline Electr & $\begin{array}{c}\text { TABLE } 4 \\
\text { ical \& Computer Engineering Faculty Often Cited }\end{array}$ & Journals b & $\mathbf{C i t}$ & tion Count \\
\hline Rank & Journal Name & $\begin{array}{c}\text { No. of } \\
\text { Citations }\end{array}$ & $\%$ & $\begin{array}{l}\text { Cumulative } \\
\%\end{array}$ \\
\hline 1 & IEEE Transactions on Geoscience and Remote Sensing & 133 & 9.0 & 9.0 \\
\hline 2 & IEEE Transactions on Power Systems & 107 & 7.3 & 16.3 \\
\hline 3 & IEEE Transactions on Power Electronics & 93 & 6.3 & 22.6 \\
\hline 4 & IEEE Transactions on Fuzzy Systems & 46 & 3.1 & 25.7 \\
\hline 5 & IEEE Transactions on Industrial Electronics & 42 & 2.9 & 28.6 \\
\hline 6 & IEEE Geoscience and Remote Sensing Letters & 40 & 2.7 & 31.3 \\
\hline 7 & IEEE Transactions on Power Delivery & 25 & 1.7 & 33.0 \\
\hline 7 & IEEE Transactions on Smart Grid & 25 & 1.7 & 34.7 \\
\hline 8 & IEEE Transactions on Image Processing & 24 & 1.6 & 36.3 \\
\hline 9 & $\begin{array}{l}\text { IEEE Transactions on Pattern Analysis and Machine } \\
\text { Intelligence }\end{array}$ & 23 & 1.6 & 37.9 \\
\hline 10 & IEEE Transactions on Industry Applications & 22 & 1.5 & 39.4 \\
\hline 11 & IEEE Transactions on Instrumentation and Measurement & 19 & 1.3 & 40.7 \\
\hline 12 & IEEE Transactions on Signal Processing & 18 & 1.2 & 41.9 \\
\hline 13 & Pattern Recognition & 17 & 1.2 & 43.1 \\
\hline 14 & Remote Sensing of Environment & 16 & 1.1 & 44.2 \\
\hline 15 & Fuzzy Sets and Systems & 15 & 1.0 & 45.2 \\
\hline 16 & Proceedings of the IEEE & 14 & 1.0 & 46.2 \\
\hline 16 & Machine Learning & 14 & 1.0 & 47.2 \\
\hline 17 & Journal of Power Sources & 12 & 0.8 & 48.0 \\
\hline 18 & IEEE Signal Processing Magazine & 11 & 0.7 & 48.7 \\
\hline 18 & IEEE Transactions on Automatic Control & 11 & 0.7 & 49.4 \\
\hline 18 & Journal of Machine Learning Research & 11 & 0.7 & 50.1 \\
\hline 19 & $\begin{array}{l}\text { IEEE Transactions on Systems, Man and Cybernetics, } \\
\text { Part B: Cybernetics }\end{array}$ & 10 & 0.7 & 50.8 \\
\hline 19 & $\begin{array}{l}\text { IEEE Journal of Selected Topics in Applied Earth } \\
\text { Observations and Remote Sensing }\end{array}$ & 10 & 0.7 & 51.5 \\
\hline 19 & IEEE Power and Energy Magazine & 10 & 0.7 & 52.2 \\
\hline 19 & IEEE Transactions on Control Systems Technology & 10 & 0.7 & 52.9 \\
\hline 19 & IEEE Transactions on Information Theory & 10 & 0.7 & 53.6 \\
\hline 20 & IEEE Transactions on Energy Conversion & 8 & 0.5 & 54.1 \\
\hline 20 & Renewable Energy & 8 & 0.5 & 54.6 \\
\hline 20 & Journal of Hydrometeorology & 8 & 0.5 & 55.1 \\
\hline 21 & Electric Power Components and Systems & 7 & 0.5 & 55.6 \\
\hline 21 & IEEE Transactions on Power Apparatus and Systems & 7 & 0.5 & 56.1 \\
\hline 22 & IEEE Transactions on Aerospace and Electronic Systems & 6 & 0.4 & 56.5 \\
\hline 22 & IEEE Signal Processing Letters & 6 & 0.4 & 56.9 \\
\hline 22 & Energy Conversion and Management & 6 & 0.4 & 57.3 \\
\hline
\end{tabular}




\begin{tabular}{|l|l|c|c|c|}
\hline \multicolumn{5}{|c|}{ TABLE 4 } \\
\hline \multicolumn{1}{|c|}{ Electrical \& Computer Engineering Faculty Often Cited Journals by Citation Count } \\
\hline Rank & \multicolumn{1}{|c|}{ Journal Name } & $\begin{array}{c}\text { No. of } \\
\text { Citations }\end{array}$ & $\begin{array}{c}\text { Cumulative } \\
\%\end{array}$ \\
\hline 22 & IEEE Transactions on Aerospace and Electronic Systems & 6 & 0.4 & 57.7 \\
\hline 23 & Applied Physics Letters & 5 & 0.3 & 58.0 \\
\hline 23 & Automatica & 5 & 0.3 & 58.3 \\
\hline
\end{tabular}

\begin{tabular}{|c|c|c|c|c|}
\hline \multicolumn{5}{|c|}{$\begin{array}{c}\text { TABLE } 5 \\
\text { Mechanical Engineering Faculty Often Cited Journals by Citation Count }\end{array}$} \\
\hline Rank & \begin{tabular}{|l|} 
Journal Name \\
\end{tabular} & $\begin{array}{c}\text { No. of } \\
\text { Citations }\end{array}$ & $\%$ & $\begin{array}{c}\text { Cumulative } \\
\%\end{array}$ \\
\hline 1 & Acta Materialia & 139 & 6.2 & 6.2 \\
\hline 2 & Materials Science and Engineering A & 74 & 3.3 & 9.5 \\
\hline 3 & International Journal of Plasticity & 56 & 2.5 & 12.0 \\
\hline 4 & Journal of Fluid Mechanics & 48 & 2.1 & 14.1 \\
\hline 5 & Applied Energy & 44 & 2.0 & 16.1 \\
\hline 6 & Scripta Materialia & 40 & 1.8 & 17.9 \\
\hline 7 & Applied Thermal Engineering & 39 & 1.7 & 19.6 \\
\hline 8 & Metallurgical and Materials Transactions A & 35 & 1.6 & 21.2 \\
\hline 9 & Energy and Buildings & 33 & 1.5 & 22.7 \\
\hline 10 & Energy Conversion and Management & 31 & 1.4 & 24.1 \\
\hline 11 & International Journal of Fatigue & 30 & 1.3 & 25.4 \\
\hline 12 & AIAA Journal & 28 & 1.2 & 26.6 \\
\hline 12 & Energy & 28 & 1.2 & 27.8 \\
\hline 13 & $\begin{array}{l}\text { International Journal of Heat and Mass } \\
\text { Transfer }\end{array}$ & 23 & 1.0 & 28.8 \\
\hline 13 & International Journal of Solids and Structures & 23 & 1.0 & 29.8 \\
\hline 14 & $\begin{array}{l}\text { Journal of the Mechanics and Physics of } \\
\text { Solids }\end{array}$ & 22 & 1.0 & 30.8 \\
\hline 15 & Materials and Design & 21 & 0.9 & 31.7 \\
\hline 16 & Rapid Prototyping Journal & 20 & 0.9 & 32.6 \\
\hline 16 & $\begin{array}{l}\text { International Journal of Machine Tools and } \\
\text { Manufacture }\end{array}$ & 20 & 0.9 & 33.5 \\
\hline 16 & Journal of Aerosol Science & 20 & 0.9 & 34.4 \\
\hline 17 & Fuel & 19 & 0.8 & 35.2 \\
\hline 18 & Journal of Computational Physics & 18 & 0.8 & 36.0 \\
\hline 18 & Journal of Materials Science & 18 & 0.8 & 36.8 \\
\hline 19 & $\begin{array}{l}\text { Fatigue \& Fracture of Engineering Materials } \\
\& \text { Structures }\end{array}$ & 17 & 0.8 & 37.6 \\
\hline 20 & $\begin{array}{l}\text { Computer Methods in Applied Mechanics } \\
\text { and Engineering }\end{array}$ & 16 & 0.7 & 38.3 \\
\hline 21 & International Journal of Heat and Fluid Flow & 15 & 0.7 & 39.0 \\
\hline
\end{tabular}




\begin{tabular}{|c|c|c|c|c|}
\hline \multicolumn{5}{|c|}{$\begin{array}{l}\text { TABLE } 5 \\
\text { Mechanical Engineering Faculty Often Cited Journals by Citation Count }\end{array}$} \\
\hline Rank & Journal Name & $\begin{array}{l}\text { No. of } \\
\text { Citations }\end{array}$ & $\%$ & $\begin{array}{c}\text { Cumulative } \\
\%\end{array}$ \\
\hline 22 & Journal of Materials Processing Technology & 14 & 0.6 & 39.6 \\
\hline 23 & Physical Review B & 13 & 0.6 & 40.2 \\
\hline 24 & $\begin{array}{l}\text { International Journal for Numerical Methods } \\
\text { in Fluids }\end{array}$ & 12 & 0.5 & 40.7 \\
\hline 24 & Journal of Energy Resources Technology & 12 & 0.5 & 41.2 \\
\hline 24 & Physical Review Letters & 12 & 0.5 & 41.7 \\
\hline 24 & Computational Materials Science & 12 & 0.5 & 42.2 \\
\hline 25 & Journal of Chemical Physics & 11 & 0.5 & 42.7 \\
\hline 25 & $\begin{array}{l}\text { International Journal of Advanced } \\
\text { Manufacturing Technology }\end{array}$ & 11 & 0.5 & 43.2 \\
\hline 26 & Mechanics of Materials & 10 & 0.4 & 43.6 \\
\hline 26 & Journal of Physical Chemistry A & 10 & 0.4 & 44.0 \\
\hline 27 & International Journal of Thermal Sciences & 9 & 0.4 & 44.4 \\
\hline 27 & Progress in Energy and Combustion Science & 9 & 0.4 & 44.8 \\
\hline 27 & Annual Review of Fluid Mechanics & 9 & 0.4 & 45.2 \\
\hline 27 & Engineering Fracture Mechanics & 9 & 0.4 & 45.6 \\
\hline 28 & Progress in Materials Science & 8 & 0.4 & 46.0 \\
\hline 28 & $\begin{array}{l}\text { International Journal for Numerical Methods } \\
\text { in Engineering }\end{array}$ & 8 & 0.4 & 46.4 \\
\hline 28 & $\begin{array}{l}\text { Journal of Mechanical Design: Transactions } \\
\text { of the ASME }\end{array}$ & 8 & 0.4 & 46.8 \\
\hline 28 & Journal of Biomechanical Engineering & 8 & 0.4 & 47.2 \\
\hline 28 & Renewable and Sustainable Energy Reviews & 8 & 0.4 & 47.6 \\
\hline 28 & Science & 8 & 0.4 & 48.0 \\
\hline 29 & Building and Environment & 7 & 0.3 & 48.3 \\
\hline 29 & Biomaterials & 7 & 0.3 & 48.6 \\
\hline 29 & $\begin{array}{l}\text { International Journal of Computational Fluid } \\
\text { Dynamics }\end{array}$ & 7 & 0.3 & 48.9 \\
\hline 30 & Flow, Turbulence and Combustion & 6 & 0.3 & 49.2 \\
\hline 30 & Experimental Thermal and Fluid Science & 6 & 0.3 & 49.5 \\
\hline 30 & Annual Review of Materials Science & 6 & 0.3 & 49.8 \\
\hline 30 & $\begin{array}{l}\text { JOM: The Journal of The Minerals, Metals \& } \\
\text { Materials Society }\end{array}$ & 6 & 0.3 & 50.1 \\
\hline 31 & International Journal of Engine Research & 5 & 0.2 & 50.3 \\
\hline 31 & International Journal of Impact Engineering & 5 & 0.2 & 50.5 \\
\hline 31 & Heat Transfer Engineering & 5 & 0.2 & 50.7 \\
\hline 31 & Physics of Fluids A & 5 & 0.2 & 50.9 \\
\hline 31 & Nature & 5 & 0.2 & 51.1 \\
\hline
\end{tabular}


There were notable differences in the age of citations among different disciplines. Moreover, in each discipline, the citation age of each source type varied. Overall, aerospace and mechanical engineering faculty seemed to cite more of the older journals. In both fields, only 82 (in aerospace) versus 84 percent (in mechanical) of the citations were from journals published in the recent 20 years; however, 20 years of journals covered up to 94 percent of the works cited by faculty in the civil and environment, electrical and computer engineering departments. Mechanical engineering faculty also tended to reference older books more often than other faculty. Additionally, in the research works of aerospace, civil and environmental, and electrical and computer engineering faculty, nearly 80 percent of book citations were less than 25 years old. But only 67 percent of books cited by mechanical engineering faculty were within that category. The detailed age distributions of highly cited resources are illustrated in figures $1-4$ by percentage.

\section{Faculty Research Collaborative Characteristics}

Last, the present work investigated research collaboration among the engineering faculty to find out other disciplines or departments on campus and across institutions that closely interacted with the engineering disciplines studied here. The findings have implications for developing collections and providing information services. In this paper, research collaboration indicates collaborating authorship (that is, coauthorship), excluding other forms of collaboration that were unnoticeable and unidentifiable in the faculty publications, such as personal communications (exchange of e-mails and telephone calls between researchers). All authors of the total 734 publications and their affiliated academic departments/institutions were recorded and examined.

Researchers from a number of outside fields contributed to the scholarly output of the faculty in the engineering disciplines under this study (see figures 5-8). While aerospace engineering faculty most frequently collaborated with researchers from mechanical engineering, chemical engineering, chemistry, and mathematics on their research articles, electrical and computer engineering faculty primarily cooperated

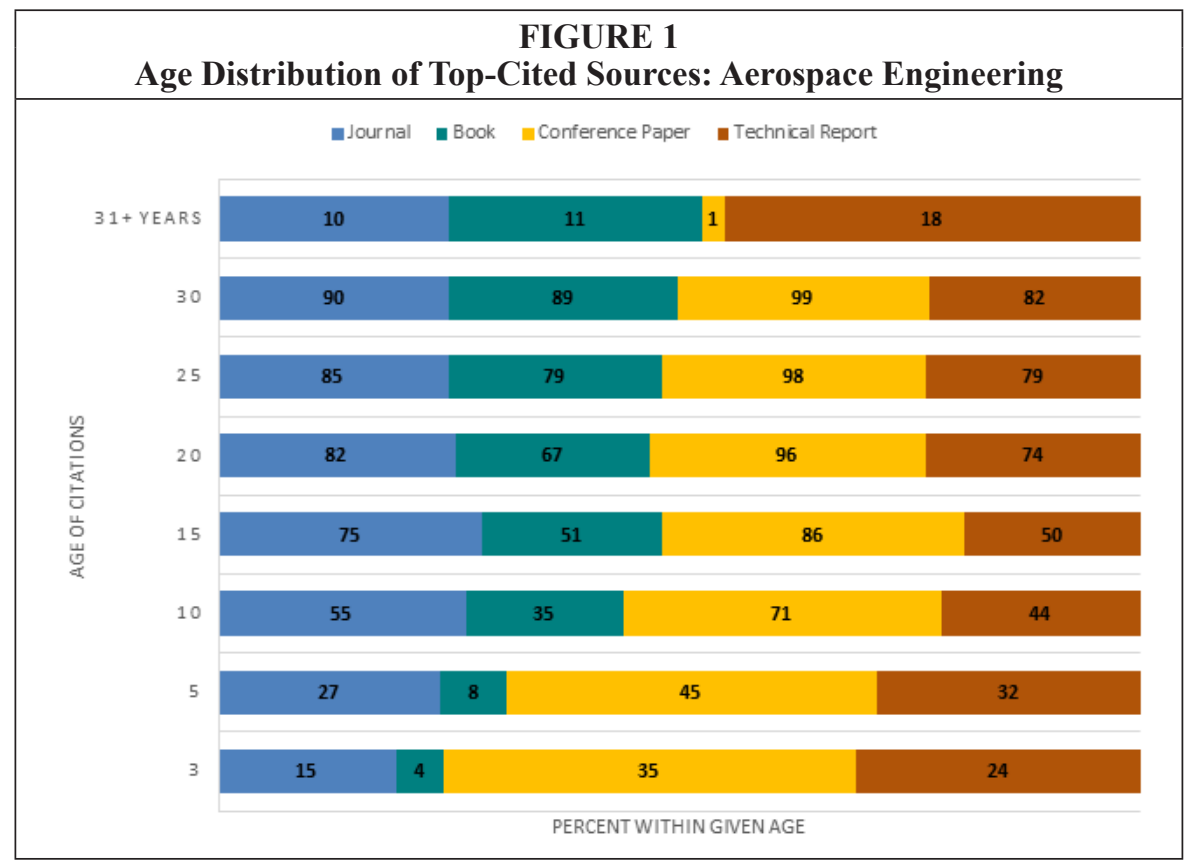




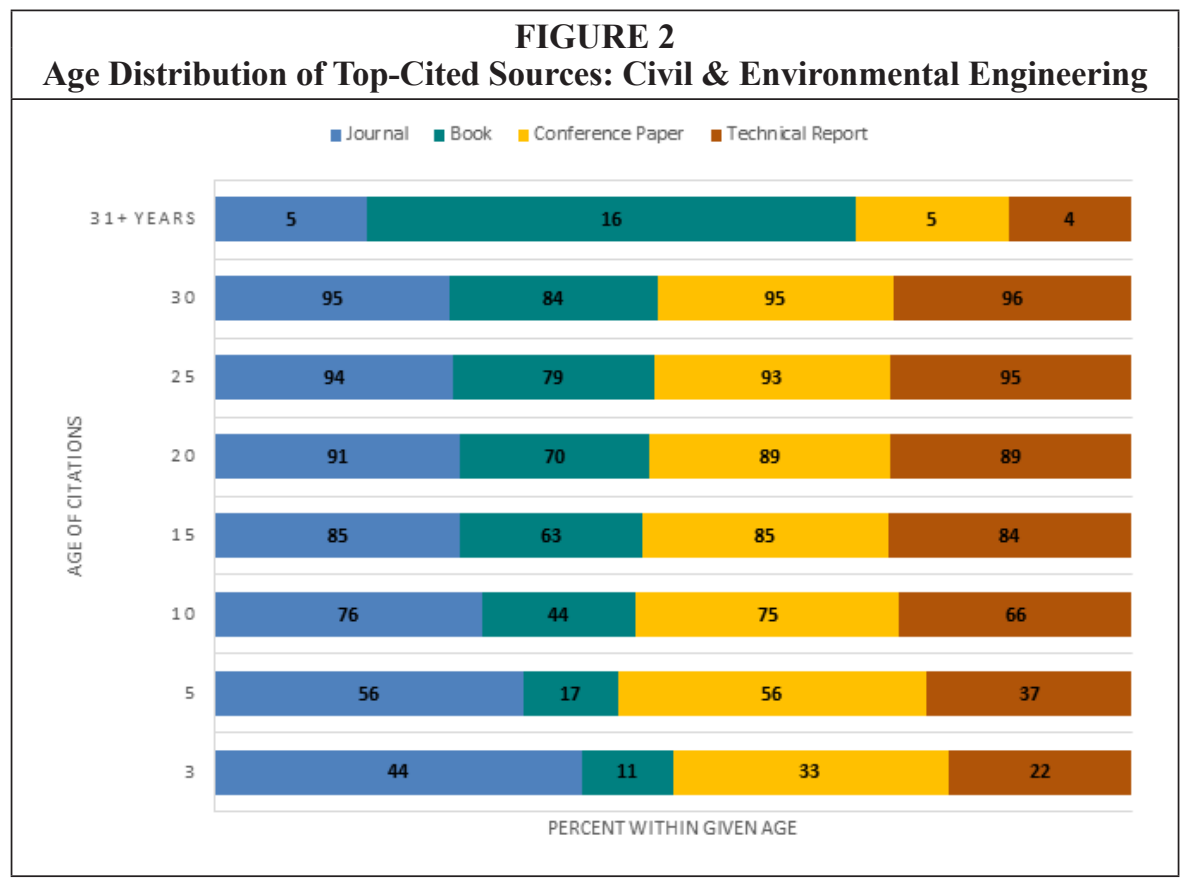

with colleagues from computer science, followed by geosciences, aviation science, and industrial technology. The top areas from which mechanical engineering faculty most often found collaborators included materials science and engineering, aerospace engineering, industrial and systems engineering, and physics and astronomy. Similar

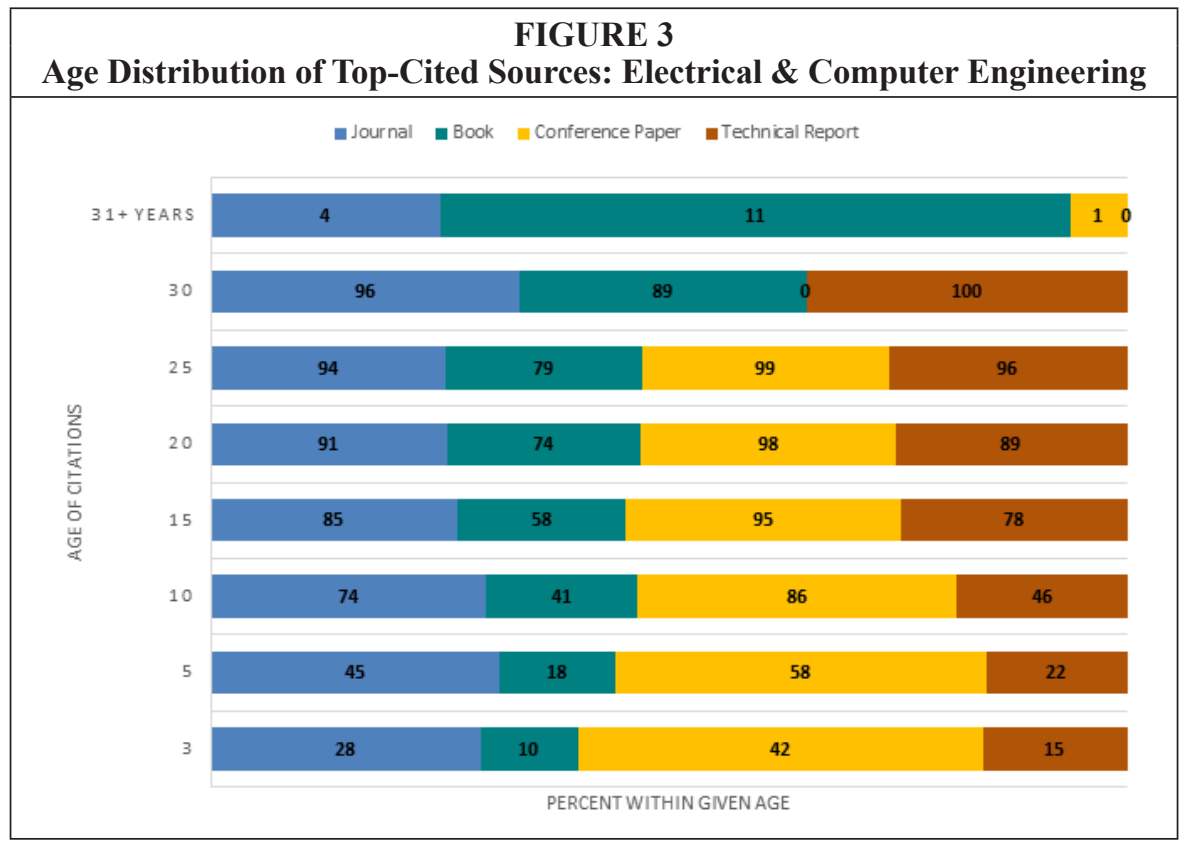




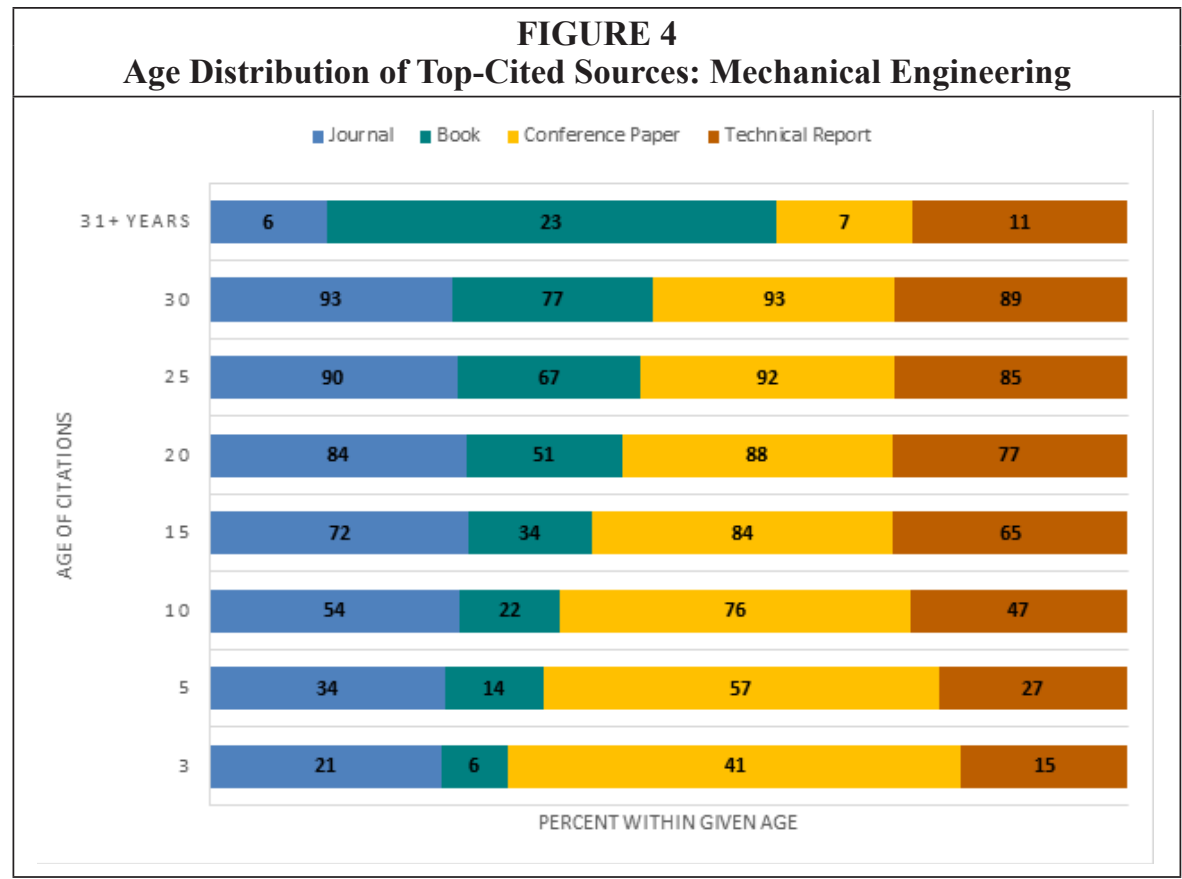

to electrical and computer engineering faculty, civil and environmental engineering faculty seemed more likely to work with researchers in their own fields. When collaborating, they often sought partners from agricultural and biological engineering, forest engineering, chemical engineering, and computer science.

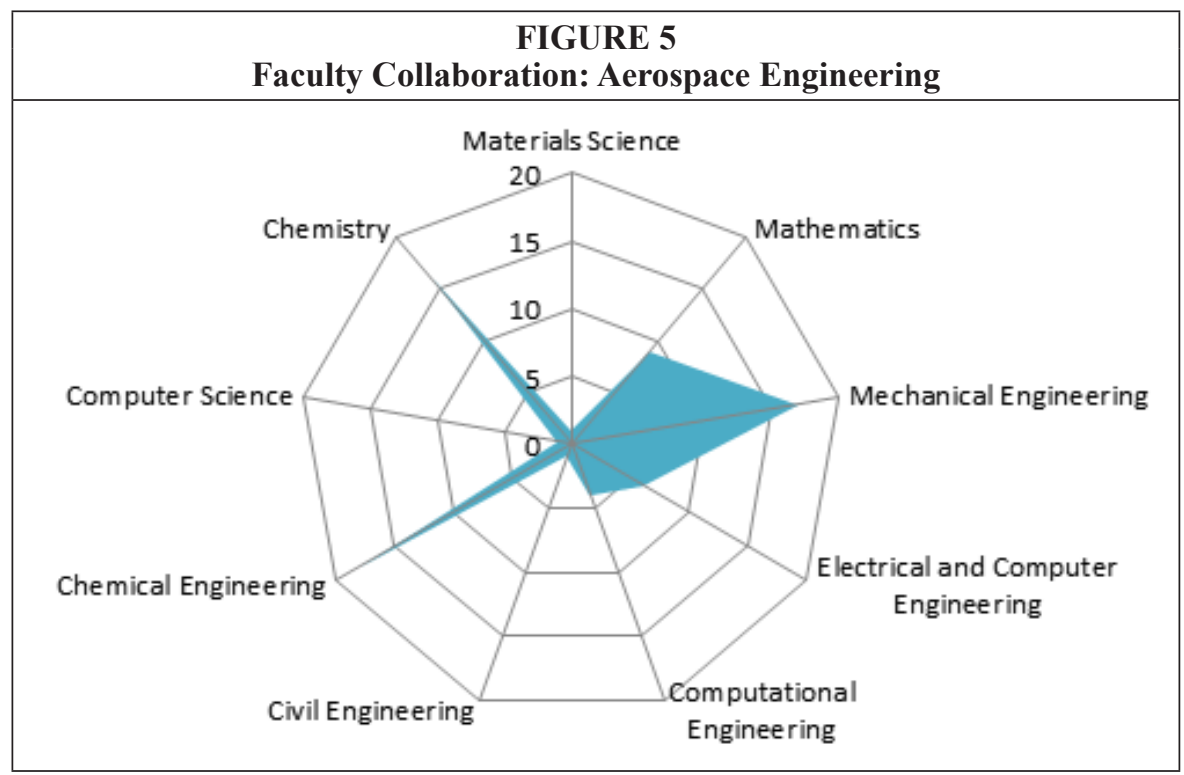




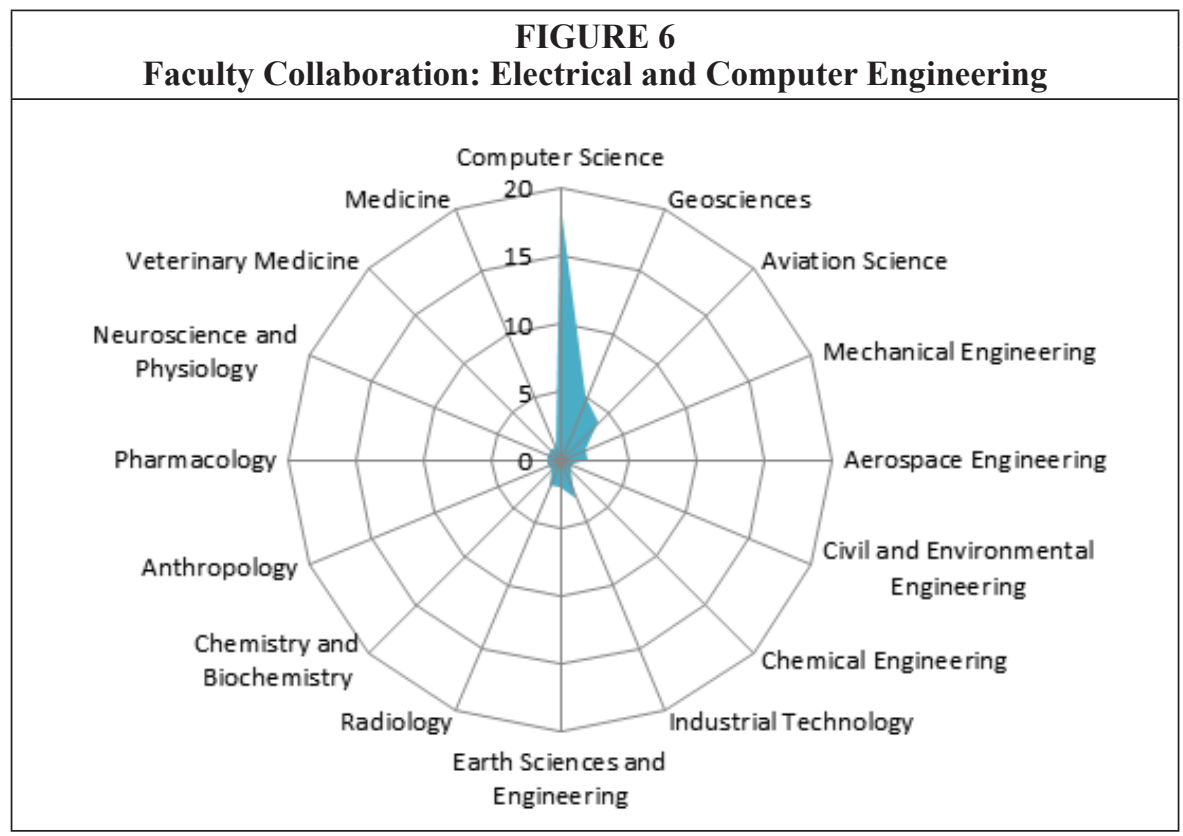

\section{Discussion}

\section{Types of Sources Cited}

Although journals' predominant role exhibited in the faculty's scholarly communication practices under this study differs from several studies involving electrical engineering and computer science, ${ }^{19}$ the finding is consistent with the majority of past citation analyses in the literature examining either the general engineering field or the subfields of engineering on which this paper focuses. The study confirms that conference papers are pivotal

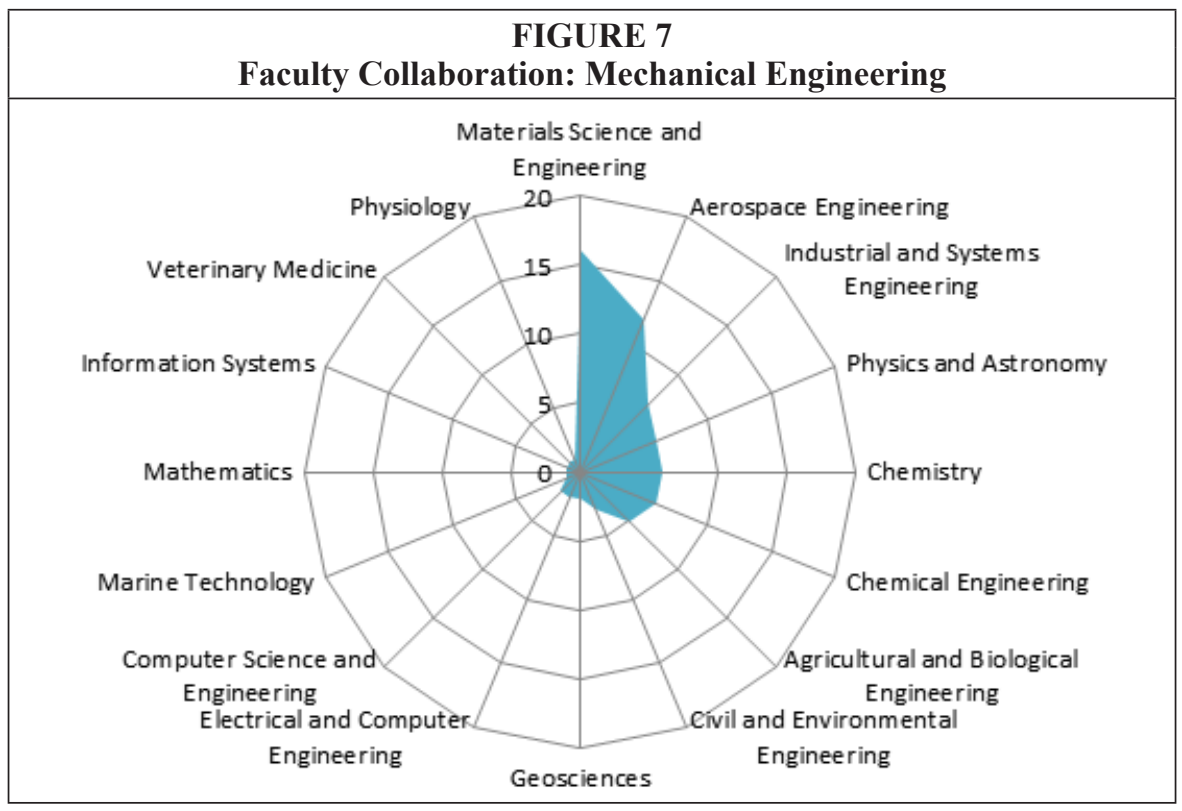




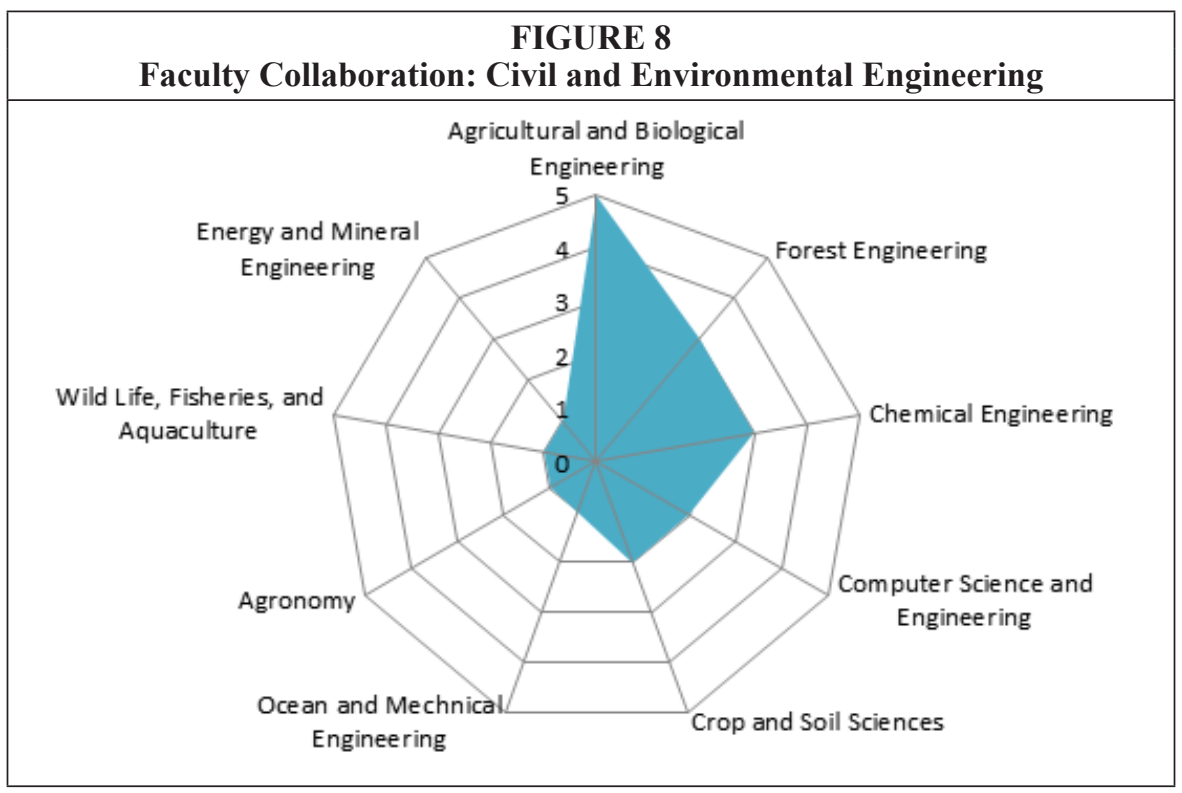

to engineering research, especially to electrical and computer engineering. Two prior studies of sixteen engineering disciplines as a whole also pointed out high frequency of conference citations, reporting that conference papers ranked as the second regularly cited source type in the professional engineering literature, preceding monographs. ${ }^{20}$

As table 1 shows, the engineering faculty cite books and technical reports relatively frequently. Particularly in civil and environmental engineering, faculty seemed more inclined to cite technical reports rather than conference papers. The high rate of citations to technical reports obtained in this study corresponds to the findings of Kirkwood's study of civil engineering theses and dissertations and Brush's study of master's theses involving civil engineering, ${ }^{21}$ but conflicts that of Curtis's study of the professional civil engineering journal literature..$^{22}$ A closer investigation of the technical reports revealed that many of them were produced by government agencies, university research centers, national/regional laboratories, and research councils. This kind of grey literature was often openly available on the web, largely via TRID (Transport Research International Documentation), a database devoted to transportation research. This finding may suggest an opportunity to promote the local institutional repository. Efforts will be put into action to communicate with and encourage the faculty to contribute to the university's institutional repository, since they are already familiar with and have taken advantage of subject repositories. As for book use, unlike the results of some earlier studies conducted before the $1990 \mathrm{~s},{ }^{23}$ but in line with evidences recently reported ${ }^{24}$ this study noticed that, overall, the use of books declined. Interestingly, a citation study comparing engineering theses from two years, 1991 and 2011, showed that references to conference papers increased significantly in 2011, while citation counts to monographs decreased. ${ }^{25}$ The changes may be because up-to-date information becomes more important to engineers, and research in books could easily turn out to be outdated, due to publication delay. Or the changes are simply because conference papers are easier to access through the web or library online databases. Further research is needed to see whether electronic books would impact engineering researchers' book use patterns. At this time, existing data cannot support a generalization that conference papers are more preferred than books in all engineering disciplines. 
Electrical and computer engineering faculty seemed to cite more web resources $(3.3 \%)$ in their research works. It is interesting to see a similar result. In her examination of citation patterns in STEM fields, Kelly found that web materials accounted for 5 percent of the resources that electrical engineers referenced. ${ }^{26}$ The rate was the highest among the STEM engineering subfields that she studied. The comparatively high percentages of web citations might indicate that electrical engineers place more emphasis on timeliness or recentness of information. Although the present study found that standards were only sporadically used across the engineering fields, the particularly low use of standards by mechanical engineering faculty is surprising. It contrasts what was observed in the local library, that mechanical engineering students requested standards frequently. Maybe standards are more likely used in the teaching-learning setting, and testing materials for application is not the focus of scholarly articles. Government documents and patents were rarely used. The observation agreed with previous citation studies related to engineering faculty or professional engineers (see the literature review section). Interestingly, the current research noticed that aerospace engineering faculty cited dissertations or theses more frequently, with a citation rate close to 2 percent $(1.9 \%)$. This number was almost identical to that announced in the citation analysis of aerospace engineering faculty at Texas A\&M. In that study, Stephens et al. revealed that theses and dissertations were the fourth most commonly cited source type (ranked before technical reports), composing 1.8 percent of the total citations. ${ }^{27}$ The various material types and usage rates revealed in each of the engineering fields denote that researchers in diverse disciplines have distinctive practices in using information sources. The results also suggest that, when allocating funds for engineering collection building, the priority should be given to journal publications first, and then selectively increase conference proceedings.

\section{Highly Cited Journals}

As costs of serial subscriptions continue to escalate, learning about the journals that faculty usually consult will help librarians evaluate existing collections for various subject areas and make the best use of limited budgets. The current study ranks highly cited journals by department or discipline for improving local collection development and liaison activities. A correlative analysis with the frequently cited journals by Texas A\&M aerospace engineering faculty shows that about 45 percent of the titles identified by Stephens et al. are present in this work..$^{28}$ In both studies, other than some highly cited discipline-specific journals, titles for cross-disciplinary research such as Journal of Applied Physics and Polymer appeared often in aerospace engineering faculties' scholarly works. Additionally, eight journals on the present study's frequently cited journal list for civil and environmental engineering are among all nine, except one, top cited environmental engineering journals that Kelly determined for professional environmental engineers. ${ }^{29}$ The overlap observed in the two studies confirms the importance of these journals to environmental engineering research. With regard to the journal use in electrical engineering, according to Coile's 1969 study, 50 percent of periodical references that electrical and electronics engineers cited only came from 18 journals. ${ }^{30}$ This study, however, notices that many more journals $(n=38)$ are needed to satisfy 50 percent of journal references. Regardless of time period, IEEE transactions are consistently ranked high on frequently cited journal lists. Very few studies have addressed mechanical engineering, particularly relating to faculty or professional engineers. As indicated earlier in the literature review section, the only study found that was related to faculty or professional engineering is Kim's analysis of Korean researchers in physics and mechanical engineering. ${ }^{31}$ However, Kim did not compile highly cited journals by mechanical engineers, so a comparison between the two studies will not work. 
From tables 2 through 5, the wide array of journal titles crossing a number of subject areas reflects the interdisciplinary scope of these engineering fields. Of the top-ranked journals, Energy Conversion and Management was referenced by faculty in all four departments, and Renewable Energy by three departments. A few other energy-related titles also appeared on the frequently cited journal lists. The high frequency of energy journals reveals the research area of particular interest to some engineering faculty at MSU. Although the library holds all energy-related journals on the lists, reviewing current materials in the energy field should be undertaken to decide any possible additions. For the examined disciplines, there were another 18 journals cross-listed in the highly cited journal rankings. These resources provide the library with evidence to determine an essential set of journal titles and also help subject specialists to gain a better understanding of engineering research. For the 167 most heavily cited journals by the engineering faculty studied, MSU Libraries hold 98 percent of the titles via print and journal package subscriptions. The 2 percent $(n=3)$ of the journals that the library currently does not own should be added to our core collection. These specific journals reflect their actual importance to the engineering faculty at the institution.

\section{Age Distribution of Most Cited Sources}

All the disciplines showed that more than half of the journal articles and more than 70 percent of conference papers cited were 10 years old or less. This affirms that engineering researchers generally depend on new literature. Overall, 66 percent of books cited were within 20 years old. The study's results are rather similar to the findings of earlier studies of citation practices of engineers. For instance, Musser and Conkling noted that 50 percent of journal citations were 8 years old or less, and 75 percent of conference papers and books were within 9 and 19 years old, respectively. ${ }^{32}$ In Young's study, 50 percent of journals, 75 percent of conference papers and books were within 9,11 , and 22 years old, respectively. ${ }^{33}$ In their study of Canadian civil engineering and computer science faculty, Spence, Mawhinney, and Barsky did not break down citations into different types; this made it difficult to closely compare the ages of individual source types used in civil engineering faculty research. However, the authors stated that approximately 60 percent of references cited were less than 10 years old. ${ }^{34}$ The present study observed a slightly higher rate, showing that 65 percent of the highly cited references in civil engineering faculty's research were within 10 years old.

Older journals and books appeared more frequently in aerospace and mechanical engineering faculties' publications (see figures 1-4). Interestingly, in their citation analysis of master's theses of engineering students at MSU, Williams and Fletcher also discovered that "(o)lder materials were cited in mechanical, aerospace, and chemical engineering." 35 In her analysis of theses and dissertations from three engineering departments of University of Minnesota, Fransen revealed similar results, noting that the "average age of Aerospace Engineering literature is substantially older for all types listed." 36 One explanation for the use of older resources in aerospace and mechanical engineering research might be that the growth of their professional literature is slow, but further investigation is certainly needed to truly understand the finding. In sum, the results suggest that librarians need to carefully scrutinize candidates when deselecting older materials for these engineering subfields.

Conference papers or proceedings provide current research that engineers expect. They usually have the shortest longevity of use. For collection management in the case of MSU, it seems appropriate to retain conference proceedings for 15 years for electri$\mathrm{cal}$ and computer engineering research and 20 years for the other disciplines. Without surprise, books aged more slowly than other sources. In this study, books older than 25 years constituted 30 percent of the citations in the mechanical engineering faculty's 
publications, and 20 percent in the works of faculty in other departments, respectively. Even for engineering research, which is often viewed as the forefront of new trends, some older books still make a worthwhile contribution. The current study found that, overall, about 11 percent of books cited by the engineering faculty were more than 30 years old. The use of old books may signify the importance of foundational work. If fewer theoretical but more applied books are published, or will be published, in the engineering field, researchers may have to reference older materials, since these are the only items available for them. It is interesting to see that the oldest citation (A Treatise on Electricity and Magnetism, a classic book published in 1892) appeared in an electrical engineering faculty's article. In short, cautions should be exercised when making weeding decisions, since old books do not necessarily mean outdated or useless.

\section{Faculty Research Collaborative Characteristics}

No prior citation analyses could be found that specifically explored engineering faculties' collaboration and coauthorship patterns that are being examined in this current study; thus, the discussion here cannot relate to earlier works. Yet it is worth noting some similar findings pertinent to subject areas involved in aerospace engineering research. In their citation study for Texas A\&M, Stephens et al. analyzed subject distribution of all resources, using the Library of Congress (LC) Classification. ${ }^{37}$ They reported that the LC subclasses of the cited resources ranged from Materials of Engineering and Construction, Mechanics of Materials, and Aeronautics/Astronautics to Mathematics. As can be seen in figure 5, both approaches, research collaboration pattern vs. LC classification, support the claim that aerospace engineering is closely related to mechanical engineering and mathematics. At MSU, there were 17 collaborations with mechanical engineering and 9 with mathematics.

A comparison of the faculty collaborative characteristics with the top journals cited showed some correlation. For example, the top ten journals cited by aerospace engineering faculty mostly came from their own field and from materials science and mechanical engineering. All the top ten journals cited by electrical and computer engineering faculty were specifically published by their professional society, the Institute of Electrical and Electronics Engineers (IEEE). For civil and environmental engineering faculty, the top ten journals all fell within their subject areas. Civil and environmental engineering faculty had fewer than 20 collaborations in all, far fewer than other departments. Although the top ten journals cited by mechanical engineering faculty were largely from their own field and materials science, a journal devoted to aerospace research (AIAA Journal) ranked relatively high (No.12) on the mechanical engineers' frequently cited journals list.

Engineering research has been advancing beyond the boundaries of a single subject field. The findings of this study confirm that the discipline of engineering not only integrates knowledge from the specialized subfields of engineering, but it also draws upon perspectives from basic scientific fields, such as mathematics, physics, and chemistry. Moreover, thanks to the cross-college faculty collaboration and cross-disciplinary research encouraged by universities and funding agencies, new research and trends continue to emerge that affect higher institutions. The interaction and cooperation among various subject disciplines have implications for academic librarians and the development of services. Librarians should be prepared to respond to emerging changes. Subject specialists need to become familiar with the broader set of research sources relevant to engineering disciplines and, furthermore, to introduce them to faculty and students. It will not be surprising when such cases happen that aerospace engineering students request medical or biological information resources to complete research projects. Librarians with collection development responsibilities should keep up with current trends and build library collections that match curriculums and reflect faculty and students' needs. 


\section{Conclusion}

Different library user groups have their specific characteristics and impacts on library collections and services. This study analyzed references cited by faculty in four academic departments and associated subject disciplines: aerospace, civil and environmental, electrical and computer, and mechanical engineering. Across the disciplines, journals are the most highly cited resource type in the faculties' research works. Conference papers are the second-most frequently cited material, except in civil and environmental engineering publications. The finding of a high proportion of conference papers correlates well with those reported in recent analyses of faculty or professional engineers' research but differs from results observed in many studies of engineering graduate students' theses and dissertations, which showed greater usage of books than conference papers. The age dispersion of highly cited sources corresponds to other studies from different time periods. Although engineering faculty primarily rely on current literature, aged books remain valuable-especially those that are considered fundamental or are historically significant.

As an established method, citation analyses can develop lists of highly used journals for academic disciplines and provide insight for librarians into evaluation of titles worth of subscribing. Routinely checking the materials that researchers actually use in their scholarly works will ensure that the library acquires, maintains, and provides access to information resources that are relevant and current to researchers. These days, many libraries face restricted allocation funds. Building library collections and expanding resources require cooperative approaches among librarians. Findings gained in this study and similar ones about the citation and collaboration habits of engineering faculty will help librarians make decisions for local collections and improve their understanding of subject fields that researchers consult and collaborate, so they can provide substantial knowledge to satisfy users' information requirements. The findings can also serve as evidence-based knowledge for liaison/outreach activities and help focus our efforts to more strategically connect faculty and their students to the library. This study offers a source of data for librarians at other institutions to analyze any differences in citation behaviors among engineering faculty. With various efforts made at different institutions, we can broaden our knowledge and understanding of engineers' information use.

\section{Notes}

1. Patricia Kirkwood, "Using Engineering Theses and Dissertations to Inform Collection Development Decisions Especially in Civil Engineering" (paper presented, ASEE Annual Conference and Exposition, Austin, TX, June 14-17, 2009).

2. Virginia Kay Williams and Christine Lea Fletcher, "Materials Used by Master's Students in Engineering and Implications for Collection Development: A Citation Analysis," Issues in Science and Technology Librarianship 45 (Winter 2006), doi:10.5062/F4PG1PPR.

3. Janet Fransen, "Literature Use in Engineering and Computer Science Research: An Analysis of Works Cited in Dissertations and Theses," Issues in Science and Technology Librarianship 71 (Fall 2012), doi:10.5062/F4Q81B1B.

4. Denise A. Brush, "Engineering Master of Science Theses at Rowan University: A Citation Analysis of the First Nine Years," Science \& Technology Libraries 34, no. 2 (May 2015): 109-21.

5. Eugene Garfield, "Journal Citation Studies. 21. Engineering Journals," Current Contents, no. 27 (July 1975): 5-10.

6. Eugene Garfield, "Characteristics of Highly Cited Publications in the Engineering Sciences," Current Contents, no. 12 (Mar. 1976): 5-10.

7. Linda R. Musser and Thomas W. Conkling, "Characteristics of Engineering Citations," Science E Technology Libraries 15, no. 4 (Oct. 1996): 41-49.

8. Brian Young, "What Do Engineering Researchers Cite? A Citation Analysis Study of Sixteen Engineering Journals," Issues in Science and Technology Librarianship 75 (Winter 2014), doi:10.5062/ F44Q7RXF. 
9. Russell C. Coile, "Periodical Literature for Electrical Engineers," Journal of Documentation 8, no. 4 (1952): 209-26.

10. Russell C. Coile, "Information Sources for Electrical and Electronics Engineers," IEEE Transactions on Engineering Writing and Speech EWS 12, no. 3 (Oct. 1969): 71-78.

11. Hae-Young Rieh, "Citation Analysis: A Case Study of Korean Scientists and Engineers in Electrical and Electronics Engineering," Proceedings of the ASIS Annual Meeting 30 (1993): 165-71.

12. Dag I.K. Sjøberg, "Confronting the Myth of Rapid Obsolescence in Computing Research," Communications of the ACM 53, no. 9 (2010): 62-67.

13. M.S. Sridhar, "Citing Patterns of Indian Space Technologists," International Library Review 17, no. 3 (1985): 259-74.

14. Jane Stephens et al., "Citation Behavior of Aerospace Engineering Faculty," Journal of Academic Librarianship 39, no. 6 (2013): 451-57.

15. Scott A. Curtis, "Informing Collection Development through Citation Examination of the Civil Engineering Research Literature" (paper presented, ASEE Annual Conference and Exposition, Vancouver, British Columbia, June 26-29, 2011).

16. Michelle Spence, Tara Mawhinney, and Eugene Barsky, "How Much Is Enough? Examining Computer Science and Civil Engineering Citation Data to Inform Collection Development and Retention Decisions in Three Large Canadian University Libraries," Issues in Science and Technology Librarianship 71 (Fall 2012), doi:10.5062/F4ZS2TF7.

17. Mee-Jean Kim, "Citation Patterns of Korean Physicists and Mechanical Engineers: Differences by Type of Publication Source and Type of Authorship," Scientometrics 55, no. 3 (Nov. 2002): 421-36.

18. Madeline Kelly, "Citation Patterns of Engineering, Statistics, and Computer Science Researchers: An Internal and External Citation Analysis across Multiple Engineering Subfields," College \& Research Libraries 76, no. 7 (Nov. 2015): 859-82.

19. Williams and Fletcher, "Materials Used by Master's Students in Engineering," doi:10.5062/ F4PG1PPR; Jessica Kayongo and Clarence Helm, "Relevance of Library Collections for Graduate Student Research: A Citation Analysis Study of Doctoral Dissertations at Notre Dame," College \& Research Libraries 73, no. 1 (Jan. 2012): 47-67; Kelly, "Citation Patterns of Engineering, Statistics, and Computer Science Researchers," 859-82; Erhard Rahm, "Comparing the Scientific Impact of Conference and Journal Publications in Computer Science," Information Services \& Use 28, no. 2 (Apr. 2008): 127-28; Jacques Wainer, Henrique Przibisczki de Oliveira, and Ricardo Anido, "Patterns of Bibliographic References in the ACM Published Papers," Information Processing and Management: An International Journal 47, no. 1 (Jan. 2011): 135-42.

20. Musser and Conkling, "Characteristics of Engineering Citations," 41-49; Young, "What Do Engineering Researchers Cite?" doi:10.5062/F44Q7RXF.

21. Kirkwood, "Using Engineering Theses and Dissertations"; Brush, "Engineering Master of Science Theses at Rowan University," 109-21.

22. Curtis, "Informing Collection Development through Citation Examination."

23. Garfield, "Journal Citation Studies. 21. Engineering Journals," 5-10; Coile, "Periodical Literature for Electrical Engineers," 209-26; Sridhar, "Citing Patterns of Indian Space Technologists," 259-74.

24. Rieh, "Citation Analysis: A Case Study," 165-71; Musser and Conkling, "Characteristics of Engineering Citations," 41-49; Young, "What Do Engineering Researchers Cite?" doi:10.5062/ F44Q7RXF; Stephens et al., "Citation Behavior of Aerospace Engineering Faculty," 451-57.

25. James Bierman, "A Citation Study of Engineering Masters Theses at the University of Oklahoma: Comparing the Years 1991 and 2011," Science \& Technology Libraries 31, no. 4 (Oct. 2012): 412-25.

26. Kelly, "Citation Patterns of Engineering, Statistics, and Computer Science Researchers," 859-82.

27. Stephens et al., "Citation Behavior of Aerospace Engineering Faculty," 453.

28. Ibid., 454.

29. Kelly, "Citation Patterns of Engineering, Statistics, and Computer Science Researchers," 870.

30. Coile, "Information Sources for Electrical and Electronics Engineers," 71.

31. Kim, "Citation Patterns of Korean Physicists and Mechanical Engineers," 421-36.

32. Musser and Conkling, "Characteristics of Engineering Citations," 41-49.

33. Young, "What Do Engineering Researchers Cite?" doi:10.5062/F44Q7RXF.

34. Spence, Mawhinney, and Barsky, "How Much Is Enough?" doi:10.5062/F4ZS2TF7.

35. Williams and Fletcher, "Materials Used by Master's Students in Engineering," doi:10.5062/ F4PG1PPR.

36. Fransen, "Literature Use in Engineering and Computer Science Research," doi:10.5062/ F4Q81B1B.

37. Stephens et al., "Citation Behavior of Aerospace Engineering Faculty," 451-57. 